\title{
The Impact of Laboratory Quality Management System Implementation on Quality Laboratory Service Delivery in Health Center Laboratories of Oromia Region, Ethiopia
}

\author{
Daba Mulleta ${ }^{1, *}$ \\ Fraol Jaleta ${ }^{2} *$ \\ Haile Banti ${ }^{3}$ \\ Bayissa Bekele ${ }^{2}$ \\ Wake Abebe 4 \\ Henok Tadesse ${ }^{5}$ \\ Legesse Eshetu ${ }^{6}$ \\ Adinew Zewdu ${ }^{6}$ \\ Abera Botore ${ }^{7}$ \\ Lamessa Tadesse ${ }^{8}$ \\ Tessema Debela ${ }^{9}$ \\ 'Chief Executive Officer of Adama Public Health \\ Research and Referral Laboratory Center, Adama, \\ Ethiopia; ${ }^{2}$ Department of Research and Public \\ Health Emergency preparedness, Adama Public \\ Health Research and Referral Laboratory Centre, \\ Adama, Ethiopia; ${ }^{3}$ Quality Manager, Adama Public \\ Health Research and Referral Laboratory centre, \\ Adama, Ethiopia; ${ }^{4}$ Department of Referral and \\ diagnosis process, Adama, Public Health Research \\ and Referral Laboratory Centre, Adama, Ethiopia; \\ ${ }^{5}$ Columbia University-International Care for AIDS \\ care and Treatment Program, Gambela, Ethiopia; \\ ${ }^{6}$ Department of Capacity Building, Ethiopian Public \\ Health Institute, Addis Ababa, Ethiopia; ${ }^{7}$ Resource \\ mobilization and community participation \\ Directorate, Oromia Regional Health Bureau, \\ Addis Ababa, Ethiopia; ${ }^{8}$ Health Policy, Budgeting, \\ Planning and monitoring and Evaluation Director, \\ Oromia Regional Health bureau, Addis Ababa, \\ Ethiopia; ${ }^{P}$ Public Health Emergency Management \\ and Health Research directorate, Oromia Regional \\ Health Bureau, Addis Ababa, Ethiopia
}

*These authors contributed equally to this work.

Correspondence: Fraol Jaleta Email firanoljakol387@gmail.com

\begin{abstract}
Continual improvement of laboratory quality service is vital to ensure accuracy, reliability, and timeliness of laboratory results. Implementation of the quality management system is an effective way of monitoring and assuring laboratory quality service. The objective of this study is to assess the impact of laboratory quality management system implementation on improving quality laboratory service in the health centers of Oromia region.

Methods: An institutional-based cross-sectional study was conducted in 89 health centers from March 27, 2019 to June 30, 2019 in Oromia. Data were collected using a nationally established laboratory quality management system implementation assessment checklist for health center laboratories. It was analyzed by SPSS version 20 and significantly associated variables with improved laboratory quality services were identified. The status of laboratory quality management system implementation in each laboratory was determined by achievement of star levels. Results: Seventy-one (79.8\%) of the total health center laboratories achieved star zero, $6(6.7 \%)$ star one and $9(10.1 \%)$ star two. Only $3(3.4 \%)$ of the total participated laboratories achieved star three. Availability of SSOPs (AOR $[95 \% \mathrm{CI}]=7.5$ ([1.10-51.54])), preventive maintenance (AOR $[95 \% \mathrm{CI}]=9.34([1.15-80.95]))$, review of customer satisfaction $(\mathrm{AOR}[95 \% \mathrm{CI}]=15([2.87-$ $80.82]))$, verification of results $(\mathrm{AOR}[95 \% \mathrm{CI}]=4.07([1.16-14.36]))$, availability of specimen guideline $(\mathrm{AOR}[95 \% \mathrm{CI}]=5.91([1.48-23.60]))$, availability of established quality indicators $(\mathrm{AOR}[95 \% \mathrm{CI}]=5.51([1.15-26.43]))$ and quality plan $(\mathrm{AOR}[95 \% \mathrm{CI}]=4.69([1.37-16.07]))$ were significantly associated with improved quality of laboratory service.

Conclusion and Recommendation: About 20.2\% of the health center laboratories provide improved laboratory service and achieved greater than star zero. Availability of SSOP, proper handling of documents, preventive maintenance, staff regular meetings, review of customer satisfaction, quality plan, verification of results, availability of specimen guideline, and availability of established quality indicators were the predictors of quality of laboratory service. Technical and managerial support by regional laboratories, facility management, and regional health bureau is vital for implementation of LQMS to improve laboratory quality services.
\end{abstract}

Keywords: quality management system, health center, service, Oromia

\section{Background}

Medical laboratories play a significant role in determining clinical decisions and providing Clinicians with a clue in the treatment and management of diseases. An effective method that is vital for laboratories to achieve accreditation to 
international standards is a very useful tool for countries to improve the quality of laboratory services for customer satisfaction that are benefited from the services. ${ }^{1}$

The improvement of laboratory quality systems leads to accreditation that gives formal recognition of the technical competence of a laboratory to perform specific tests and assures the validity of the results to the customers by fulfilling the competence and quality requirements stated in ISO15189:2012. ${ }^{2}$

To reach the highest level of accuracy and reliability of quality service, the implementation of a quality management system that depends on good management of all 12 quality essentials namely; organization, personnel, equipment, purchasing and inventory, process control, information management, documents and records, occurrence management, assessment, process improvement, customer services, and facility and safety are unquestionably crucial for effective provision of laboratory quality services. $^{3}$

Laboratory quality management systems should be applied during the entire path of workflow in the laboratory and administrative considerations that may indirectly influence the quality and efficiency of the laboratory operation is addressed through effective implementation of a laboratory quality management system. ${ }^{3}$

To improve and sustain continual improvement of quality services, laboratory personnel must comply with procedures and ensure that the stated requirements for all laboratory activities are fulfilled. Laboratory errors directly affect patients in terms of treatment time and satisfaction. Thus, laboratories should have proper QMS in place to ensure the quality of all laboratory services. ${ }^{4}$

Several studies indicated various factors such as top management commitment, knowledge of quality management system, monitoring and feedback, time and cost, training, and education as the main factors affecting the quality management system. Internal motivation, external environment pressure, staff commitments, customer satisfaction, employee resistance and qualification of laboratory personnel, training, continual professional developments in turn affect the quality laboratory service in reporting accurate and reliable results. ${ }^{5,6}$

Despite the current progress of health sciences in the improvement of health care provision, the availability and accessibility of quality health care remains a challenge across the world, especially in low-income countries. ${ }^{7}$
Laboratory services in sub-Saharan African countries are known to suffer many challenges, including poor infrastructure, inadequate human resource capacity, insufficient on-site supervision, and weak underlying health systems which are the major reason for the non-implementation of QMS. ${ }^{8,9}$

The coverage and quality of laboratory services all over Africa are insufficiently implemented and quality service provided by individual laboratories is a critical concern. In 2013, the assessment and evaluation of accredited laboratories in sub-Saharan Africa indicated that $75 \%$ of countries had no medical laboratories that met internationally recognized quality requirements. ${ }^{6}$

The World Health Organization's Regional Office for sub-Saharan Africa has recommended that member countries improve the performance standards of their laboratories by implementing laboratory LQMS through Stepwise Laboratory Improvement Toward Accreditation (SLIPTA). ${ }^{10}$

Despite Ethiopia adopting a Strengthening Laboratory Management toward Accreditation (SLMTA) program in 2009 to accelerate LQMS and prepare laboratories for accreditation, the implementation of LQMS in all tiers of laboratories particularly in the health center is very weak resulting in poor quality laboratory services. ${ }^{10}$

Laboratories in the health system of Ethiopia are categorized in four tiers: district/health center, hospital, regional and national laboratory. The national laboratory oversees the overall system of regional laboratories which in turn supports and oversees hospital and health center laboratories. ${ }^{11}$

According to Ethiopian standard health care requirements, health facilities at the primary level of the health system, health centers, should provide basic laboratory examinations including hematology, parasitological, urinalysis and body fluid analysis, serological test, and bacteriology clinical microscopy. The health center shall monitor quality assurance activities throughout workflow for continual service improvements. ${ }^{12}$

To ensure laboratory quality management system implementation and improve laboratory services to established national standards in the health center laboratories, the assessment checklist for quality and competence is designed to the scope of lower level laboratories in Ethiopia. This assessment checklist contains 12 sections with a total of 76 questions and a total of 188 points. The five-star level is designed and awarded based on the total score achievement for each health center laboratory. ${ }^{13}$

In the Oromia region, hospitals and health center laboratories are supported, mentored, and overseen by Adama 
public health research and referral laboratory, Nekemte public health research and referral laboratory, and Shashemene public health research and referral laboratory. A total of 49 hospitals and 2 regional labs in Oromia are enrolled in SLPTA and 100 health centers are enrolled in LQMS implementation since the program started. Twelve of the total enrolled hospitals have achieved greater than star one based on WHO AFRO-Checklists assessment to strive for accreditation to ISO15189:2012. ${ }^{14}$

The implementation of an effective quality management system has a vital role in reducing and detecting laboratory errors in all tiers of laboratories. A laboratory that implements the QMS model can have the ability to effectively detect and reduce errors, a higher probability of meeting customer expectations, more effective and efficient functions and a greater chance of successful accreditation to ISO 15189:2012 evaluation, and continual improvement in quality service. ${ }^{15}$

There is a limited study that indicates factors affecting LQMS implementation in Ethiopia, particularly in health center laboratories. So, this study is aimed to assess the impact of LQMS implementation on laboratory quality service and its contributing factors in LQMS enrolled health centers in the Oromia region.

\section{Methods and Materials}

\section{Study Setting and Materials}

An institutional-based cross-sectional study was conducted from March 27, 2019, to June 30, 2019 in the Oromia region which included 21 zones. Oromia region is the largest region with the highest population located at the center of the country. There are 3 regional laboratories, 9 blood banks, a total of 66 public hospitals, and 1363 public health centers currently providing laboratory services in the region. ${ }^{14}$ The study was aimed to be conducted in all 91 laboratory quality management systems enrolled in public health centers from 2014-2018 that provide functional laboratory services for the population in the region. However, three health centers were excluded from the study due to security issues during data collection and the study was finally conducted in 89 LQMS enrolled health centers.

\section{Data Collection Tools and Technique}

Data were collected by laboratory quality management implementation status assessment checklists for health center laboratories developed and approved by Ethiopian Public Health Institute. This checklist consists of laboratory professionals, documentation and quality assurance, health facility and safety, and 12 laboratory quality management essential (Figure 1) related characteristics. Star levels: star zero (0-105 points), star one (106-124 points), star two (125-143 points), star three (144-162 points) are designed and included in the checklist to categorize laboratories' laboratory service outcomes based on LQMS implementation status. Document and record reviews by nationally approved checklists and observation of laboratory operations were the primary means of data collection in all study health facilities.

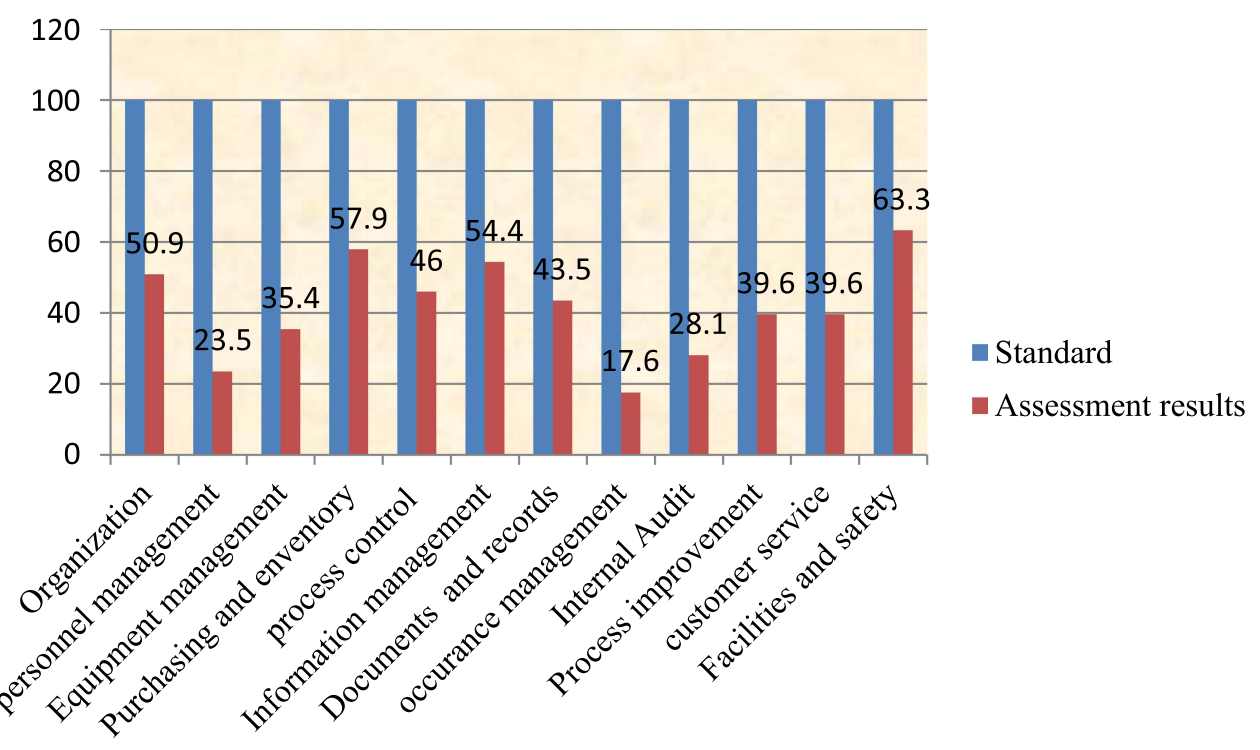

Figure I Average score of quality system essentials in LQMS enrolled health center laboratories in Oromia region. 


\section{Data Management and Analysis}

Data were first entered into Epi Info 3.5.3 and exported to SPSS version 20 for analysis. Data were summarized by graphs, charts, and tables to show laboratory quality management system implementation status. Star levels status which is nationally designed for health center laboratories and used to categorize laboratories' performance based on LQMS implementation status are identified. Frequencies and proportions were analyzed by descriptive analysis. Bivariate analysis was done to identify candidate variables for the association of dependent variables with independent variables with $\mathrm{p}$-value $<0.25$, COR and $95 \%$ CI to identify candidate variables. Multivariate analysis with p-value $<0.05, \mathrm{AOR}$, and $95 \% \mathrm{CI}$ was finally done to show the impact of LQMS implementation on quality service delivery identifying factors significantly associated with poor laboratory quality service.

\section{Results}

\section{Laboratory Professional Related Variables in LQMS Enrolled Health Centers}

A total of 124 laboratory professionals were working in 89 selected health centers. Of them, $52(41.04 \%)$ and 72 $(58.06 \%)$ were females and males, respectively. From the total participating LQMS enrolled health centers, majority of them have no duty roster, documented staff job description, a system for employee recognition, and staff motivation. More than half of health centers had a trained staff on LQMS and only $6(6.8 \%)$ of them had provided training on bio-safety and security (Table 1).

\section{Documentations and Quality Assurance Practice-Related Characteristics in LQMS Enrolled Health Centers in the Oromia Region}

A total of 54 (60.7\%), $54(60.7 \%)$ and $33(37.1 \%)$ had updated quality manuals, updated technical SOP for all tests and system SOP, respectively. Seventy-nine (88.8\%) LQMS enrolled health centers had established Turnaround Time and 57 (64\%) of them had released all results within TAT. Most of them had participated in EQA and verify results before release and less than half of participating facilities had conducted customer satisfaction surveys. A total of $53(59.5 \%)$ performed regular preventive
Table I Laboratory Professional Related Variables in LQMS Enrolled Health Center in Oromia, Ethiopia, 2019

\begin{tabular}{|l|l|l|}
\hline Variables & Frequency (\%) & Percentage \\
\hline \multicolumn{2}{|l|}{ Training given on LQMS } & $51.7 \%$ \\
\hline Yes & 46 & $49.3 \%$ \\
No & 43 & \\
\hline
\end{tabular}

Training on specimen management

\begin{tabular}{|l|l|l|}
\hline Yes & 37 & $41.6 \%$ \\
No & 52 & $59.4 \%$ \\
\hline
\end{tabular}

Training on AFB

\begin{tabular}{|l|l|l|}
\hline Yes & 58 & $65.2 \%$ \\
No & 31 & $34.8 \%$ \\
\hline
\end{tabular}

Training on malaria

\begin{tabular}{|l|l|l|}
\hline Yes & 44 & $49.4 \%$ \\
No & 45 & $50.6 \%$ \\
\hline \multicolumn{2}{|l|}{} \\
\hline Training on HIV & $15.7 \%$ \\
\hline Yes & 14 & $84.3 \%$ \\
No & 75 &
\end{tabular}

Training on bio-safety and bio-security

\begin{tabular}{|l|l|l|}
\hline Yes & 6 & $6.8 \%$ \\
No & 83 & $93.2 \%$ \\
\hline
\end{tabular}

Delegated laboratory head

\begin{tabular}{|l|l|l|}
\hline Yes & 34 & $39.2 \%$ \\
No & 55 & $61.8 \%$ \\
\hline
\end{tabular}

Delegated quality officer

\begin{tabular}{|l|l|l|}
\hline Yes & 18 & $29.3 \%$ \\
No & 71 & $79.7 \%$ \\
\hline \multicolumn{2}{|l|}{} \\
\hline Delegated safety officer & $14.6 \%$ \\
Yes & 13 & $84.5 \%$ \\
\hline Dedicated cleaner & 76 & $44.9 \%$ \\
\hline Yes & 40 & $55.1 \%$ \\
\hline No & 49 & \\
\hline Trained cleaner on bio-safety & $6.8 \%$ \\
\hline Trained & 6 & $93.2 \%$ \\
\hline Not trained & 83 & $19.2 \%$ \\
\hline Availability of job description & $80.8 \%$ \\
\hline Yes & 17 & \\
\hline No & 72 &
\end{tabular}

(Continued) 
Table I (Continued).

\begin{tabular}{|c|c|c|}
\hline Variables & Frequency (\%) & Percentage \\
\hline \multicolumn{3}{|c|}{ Availability of system for employee recognition } \\
\hline Yes & 16 & $18 \%$ \\
\hline No & 73 & $82 \%$ \\
\hline \multicolumn{3}{|c|}{ Availability system for staff motivation } \\
\hline Available & 15 & $16.9 \%$ \\
\hline Not available & 74 & $83.1 \%$ \\
\hline \multicolumn{3}{|c|}{ Proactive support from management } \\
\hline Yes & 62 & $69.7 \%$ \\
\hline No & 27 & $30.3 \%$ \\
\hline \multicolumn{3}{|c|}{ Competency of staff ever performed } \\
\hline Yes & 8 & $9 \%$ \\
\hline No & 81 & $91 \%$ \\
\hline \multicolumn{3}{|c|}{ Job satisfaction with current laboratory work } \\
\hline Yes & 58 & $65.2 \%$ \\
\hline No & 31 & $34.8 \%$ \\
\hline
\end{tabular}

Abbreviations: LQMS, laboratory quality management system; AFB, acid fast bacilli; HIV, Human Immune Virus.

maintenance for all equipment and an internal audit was conducted in $10(11.2 \%)$ health centers (Table 2).

\section{Health Facility Service and Safety Practice-Related Characteristics}

Sixty-five $(73 \%)$ of participating health center laboratories had a water supply, waste segregation practice was observed in more than half of participating laboratories, and $78(87.6 \%) .28(31.5 \%)$ of them had adequate size and layout of the laboratory room. Most of them had incinerators and separate toilets for staff and clients. About 13 (14.6) had a trained and certified safety officer (Table 3).

\section{Quality Indicator Performance in LQMS Enrolled Health Center}

Evidence of daily internal quality control (IQC) practice was observed in 64 (71.9\%) and establishment and use of TAT for all tests in $79(88.8 \%)$ participating health center laboratories. Fifty-seven (64\%) health centers released patient results within TAT. Most of the participating health centers, 87 (97.7\%), had participated in a regional EQA scheme and only 39 (43.8\%) had reviewed EQA performance and set corrective action. In the health center laboratories it was identified that service was interrupted
Table 2 Documentations and Quality Assurance Related Characteristics in LQMS Enrolled Health Centers

\begin{tabular}{|c|c|c|}
\hline Variables & & \\
\hline \multicolumn{3}{|c|}{ Standard request paper } \\
\hline Available & 47 & $52.8 \%$ \\
\hline Available & 42 & $47.2 \%$ \\
\hline \multicolumn{3}{|c|}{ Acceptance and rejection criteria } \\
\hline Available & 18 & $20.2 \%$ \\
\hline Not available & 71 & $79.8 \%$ \\
\hline \multicolumn{3}{|c|}{ Approved QM } \\
\hline Available & 54 & $60.7 \%$ \\
\hline Not available & 35 & $39.3 \%$ \\
\hline \multicolumn{3}{|c|}{ Updated lab hand book } \\
\hline Available & 45 & $50.5 \%$ \\
\hline Not available & 44 & $49.5 \%$ \\
\hline \multicolumn{3}{|c|}{ Updated SOP for all test } \\
\hline Available & 54 & $60.7 \%$ \\
\hline Not available & 35 & $39.3 \%$ \\
\hline \multicolumn{3}{|c|}{ Adherence on SOP } \\
\hline Yes & 51 & $57.3 \%$ \\
\hline No & 38 & $42.7 \%$ \\
\hline \multicolumn{3}{|c|}{ Updated SSOP } \\
\hline Available & 33 & $37.1 \%$ \\
\hline Not available & 56 & $53.9 \%$ \\
\hline \multicolumn{3}{|c|}{ Specimen guideline } \\
\hline Yes & 43 & $48.3 \%$ \\
\hline No & 56 & $51.7 \%$ \\
\hline \multicolumn{3}{|c|}{ Updated technical format } \\
\hline Available & 32 & $40 \%$ \\
\hline Not available & 57 & $60 \%$ \\
\hline \multicolumn{3}{|c|}{ Updated system format } \\
\hline Available & 27 & $30.3 \%$ \\
\hline Not available & 62 & $69.7 \%$ \\
\hline \multicolumn{3}{|c|}{ Daily IQC practice } \\
\hline Yes & 64 & $72 \%$ \\
\hline No & 25 & $28 \%$ \\
\hline \multicolumn{3}{|c|}{ TAT established for all tests } \\
\hline Yes & 79 & $88.8 \%$ \\
\hline No & 10 & $11.2 \%$ \\
\hline
\end{tabular}

(Continued) 
Table 2 (Continued).

\begin{tabular}{|c|c|c|}
\hline Variables & & \\
\hline \multicolumn{3}{|c|}{ Result released within TAT } \\
\hline Yes & 57 & $64 \%$ \\
\hline No & 32 & $36 \%$ \\
\hline \multicolumn{3}{|c|}{ Participation on EQA } \\
\hline Participate & 87 & $97.7 \%$ \\
\hline Not participate & 2 & $2.3 \%$ \\
\hline \multicolumn{3}{|c|}{ Review for EQA feedback } \\
\hline Yes & 39 & $43.8 \%$ \\
\hline No & 50 & $56.2 \%$ \\
\hline \multicolumn{3}{|c|}{ Customer satisfaction survey conducted } \\
\hline Yes & 37 & $31 \%$ \\
\hline No & 52 & $58 \%$ \\
\hline \multicolumn{3}{|c|}{ Review of customer satisfaction } \\
\hline Yes & 16 & $7 \%$ \\
\hline No & 73 & $82 \%$ \\
\hline \multicolumn{3}{|c|}{ Experience of service interruption } \\
\hline Yes & 61 & $68.5 \%$ \\
\hline No & 28 & $31.5 \%$ \\
\hline \multicolumn{3}{|c|}{ Ever conducted internal audit } \\
\hline Yes & 10 & $11.2 \%$ \\
\hline No & 79 & $88.8 \%$ \\
\hline \multicolumn{3}{|c|}{ System for inventory control } \\
\hline Yes & 53 & $59.5 \%$ \\
\hline No & 36 & $40.5 \%$ \\
\hline \multicolumn{3}{|c|}{ Adequate equipment for testing } \\
\hline Yes & 44 & $49.4 \%$ \\
\hline No & 45 & $50.6 \%$ \\
\hline \multicolumn{3}{|c|}{ Preventive e maintenance for all equipment } \\
\hline Yes & 53 & $59.5 \%$ \\
\hline No & 36 & $44.5 \%$ \\
\hline \multicolumn{3}{|c|}{ Result verification } \\
\hline Yes & 32 & $36 \%$ \\
\hline No & 57 & $64 \%$ \\
\hline \multicolumn{3}{|c|}{ Utilization of quality indicators } \\
\hline Yes & 54 & $60.6 \%$ \\
\hline No & 35 & $39.4 \%$ \\
\hline
\end{tabular}

Abbreviations: QM, quality manual; SOP, standard operating procedure; SSOP, system standard operating procedure; IQC, internal quality control; TAT, turnaround time; EQA, external quality assessment. due to reagent stock out in $82(92.1 \%)$, machine failure in $6(6.8 \%)$, and human power shortage in 1 (1.1\%) (Figure 2).

\section{Implementation of Quality System Essential Elements}

During the assessment, the highest average score is achieved in facility and safety $(63.1 \%)$ followed by purchasing and inventory $(57.9 \%)$. The average scores for implementation of documents and records and organization were $43.5 \%$ and $50.9 \%$, respectively. The lowest average score of quality essential element implementation was occurrence management (17.6\%) followed by personnel management with an average score of $23.5 \%$ (Figure 1).

\section{Laboratory Quality Management Implementation Status}

From the total of enrolled health center laboratories, 71 (79.8\%) scored between 0-105 and achieved zero stars, 6 (6.7\%) scored 106-124 points and achieved star one, 9 (10.1\%) scored 125-143 points, and achieved star two. Only 3 (3.4\%) scored 144-162 points and achieved star three. Those which achieved greater than star one on implementation are considered as improved quality service laboratories (Figure 3).

\section{The Impact of Laboratory Quality Management System Implementation and Factors Affecting Quality Laboratory Service Improvement}

Several factors were significantly associated with quality laboratory service improvement after multivariate analysis in study health center laboratories. Considering greater than star one LQMS implementation status as a dependent variable, there was significant association with availability of system SOPs (AOR $[95 \% \mathrm{CI}]=7.5$ ([1.10-51.54]), preventive maintenance (AOR[95\% CI] $=9.34([1.15-80.95])$, review of customer satisfaction (AOR[95\% CI] $=15$ ([2.87-80.82]), verification of test results $(\mathrm{AOR}[95 \% \mathrm{CI}]=4.07([1.16-14.36])$, availability of specimen guideline (AOR $[95 \%$ CI $]=5.91 \quad([1.48-$ 23.60]), availability of established quality indicators (AOR[95\% CI] $=5.51$ ([1.15-26.43]), and quality plan (AOR[95\% CI] $=4.69$ ([1.37-16.07]). 
Table 3 Health Facility Service and Safety Practice Related Characteristics

\begin{tabular}{|c|c|c|}
\hline Variables & & \\
\hline \multicolumn{3}{|c|}{ Availability of water supply } \\
\hline Yes & 65 & $73 \%$ \\
\hline No & 34 & $16 \%$ \\
\hline \multicolumn{3}{|c|}{ Backup power supply } \\
\hline Yes & 39 & $43.8 \%$ \\
\hline No & 50 & $56.2 \%$ \\
\hline \multicolumn{3}{|c|}{ Availability of waste container } \\
\hline Yes & 66 & $74.2 \%$ \\
\hline No & 23 & $25.8 \%$ \\
\hline \multicolumn{3}{|c|}{ Availability of separate toilet } \\
\hline Yes & 52 & $58.4 \%$ \\
\hline No & 37 & $41.6 \%$ \\
\hline \multicolumn{3}{|c|}{ Waste segregation practice } \\
\hline Yes & 78 & $87.6 \%$ \\
\hline No & 11 & 12.4 \\
\hline \multicolumn{3}{|c|}{ Adequate size and layout of laboratory } \\
\hline Yes & 28 & $31.5 \%$ \\
\hline No & 61 & $68.5 \%$ \\
\hline \multicolumn{3}{|c|}{ Availability of computer } \\
\hline Yes & 19 & $21.3 \%$ \\
\hline No & 70 & $78.7 \%$ \\
\hline \multicolumn{3}{|c|}{ Availability of printer } \\
\hline Yes & 8 & $9 \%$ \\
\hline No & 81 & $91 \%$ \\
\hline \multicolumn{3}{|c|}{ Availability of refrigerator } \\
\hline Available & 58 & $65.2 \%$ \\
\hline Not available & 31 & $34.8 \%$ \\
\hline \multicolumn{3}{|c|}{ Proper handling of LQMS documents } \\
\hline Yes & 37 & $39.6 \%$ \\
\hline No & 52 & $58.4 \%$ \\
\hline \multicolumn{3}{|c|}{ Keep confidentiality of patient information } \\
\hline Yes & 70 & $78.7 \%$ \\
\hline No & 19 & $21.3 \%$ \\
\hline \multicolumn{3}{|c|}{ Easilyaccessible of patient results } \\
\hline Yes & 57 & $64 \%$ \\
\hline No & 32 & $36 \%$ \\
\hline
\end{tabular}

(Continued)
Table 3 (Continued).

\begin{tabular}{|l|l|l|}
\hline \multicolumn{2}{|l|}{ Variables } & \multicolumn{2}{|l|}{} \\
\hline \multicolumn{2}{|l|}{ Availability of organizational chart } \\
\hline Yes & 17 & $19.1 \%$ \\
No & 72 & $80.9 \%$ \\
\hline \multicolumn{2}{|l|}{ Availability of quality plan } & $20.2 \%$ \\
\hline Yes & 18 & $79.8 \%$ \\
No & 71 & \\
\hline
\end{tabular}

Abbreviation: LQMS, laboratory quality management system.

Those health centers which showed evidence of root cause analysis for nonconformity were 25.2 times more likely to provide improved quality laboratory service than those which did not perform root cause analysis.

Health center laboratories in which laboratory professionals performed equipment preventive maintenance were 9.34 times more likely to show better quality laboratory service than those which did not perform.

Health center laboratories in which review of customer satisfaction and EQA feedback were observed to be 15.24 and 34.88 times more likely to provide improved quality laboratory services, respectively.

Moreover, health centers in which evidence of result verification was observed were 4.07 times more likely to show better quality laboratory service than those in which no evidence of result verification was observed. Additionally, laboratories which had evidence of established quality indicators and a quality plan were 5.51 and 4.69 times more likely to contribute good quality laboratory service than those which did not show the evidence, respectively (Table 4).

\section{Discussion}

The study was conducted in 89 public health centers of the Oromia region which has enrolled in LQMS implementation by standard LQMS checklists developed from AFROChecklists for health centre laboratories. In this study, training on LQMS, which is the base for providing improved quality laboratory services, has been provided for laboratory professionals in greater than $50 \%$ of laboratories. This study is consistent with the studies conducted in other areas in the proportion of employees provided with training in LQMS implemented laboratories. ${ }^{15-17}$ This study is inconsistent 


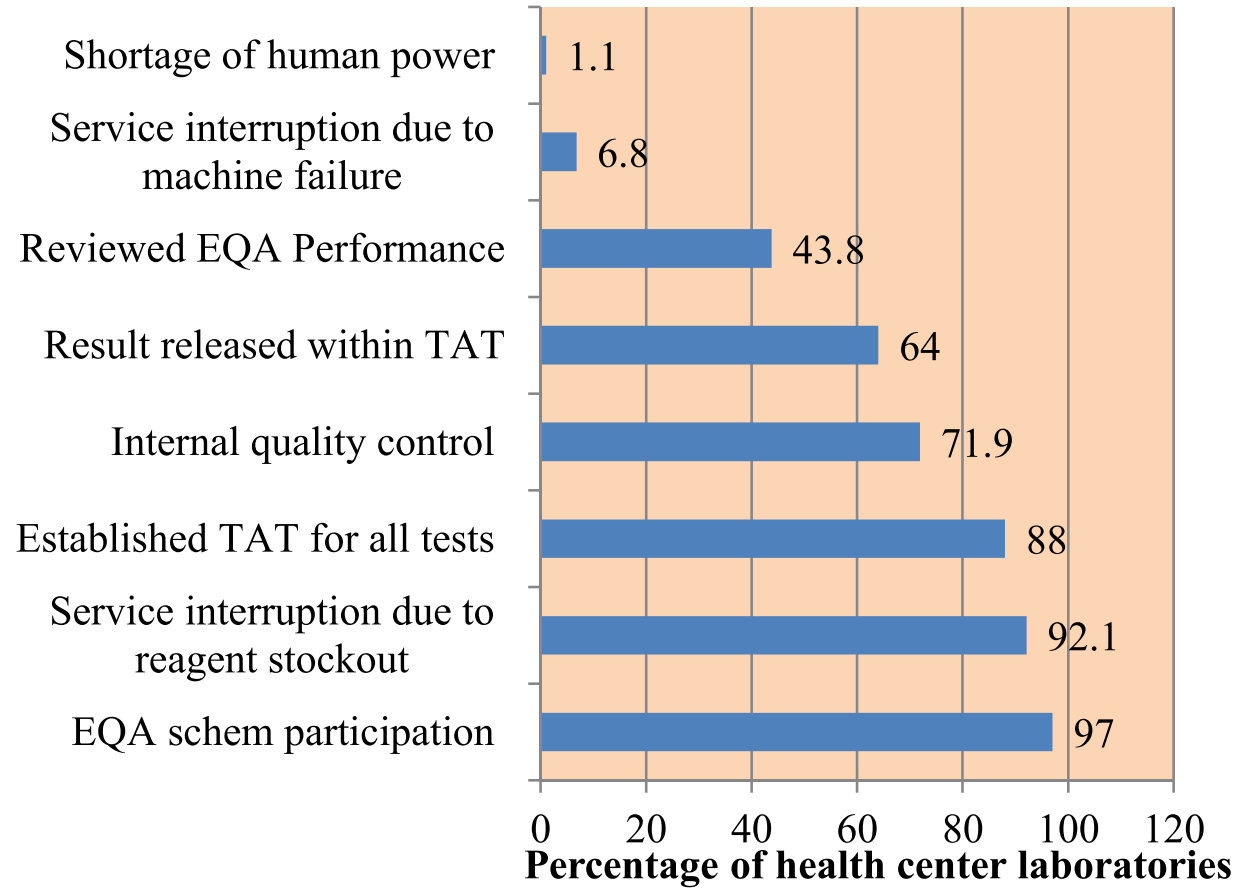

Figure 2 Quality indicator performance in LQMS enrolled health center laboratories in Oromia region.

\section{LQMS Iplementation status}

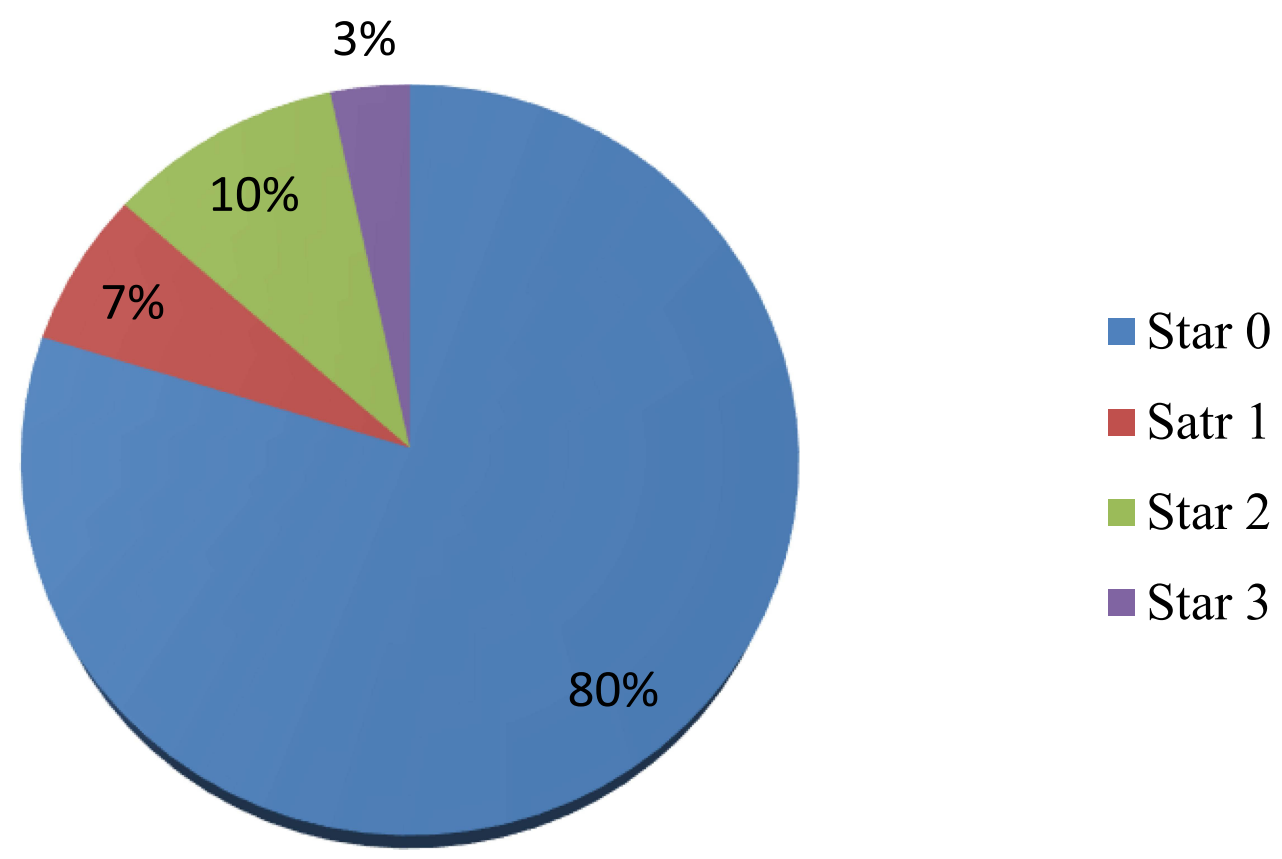

Figure 3 Laboratory quality management system implementation status in health center laboratories in Oromia.

with the study conducted in Kenya in which few employees (30\%) had only formal training on LQMS. ${ }^{5}$ The possible variation might be the difference in the type of health facilities, method of data collection, and the variation in the commitment of top management to initiate employee training on the quality management system. 
Table 4 Multivariate Analysis of Factors Affecting Laboratory Quality Service Delivery

\begin{tabular}{|c|c|c|c|c|c|c|}
\hline Variable & Frequency (\%) & COR & $95 \% \mathrm{Cl}$ & AOR & $95 \% \mathrm{Cl}$ & p-value \\
\hline \multicolumn{7}{|c|}{ Availability of SSOP } \\
\hline Yes & $33(17.1 \%)$ & 14.7 & $3.82-56.78$ & 7.50 & $1.10-51.54$ & 0.041 \\
\hline No & $56(81.9 \%)$ & 1 & & & & \\
\hline \multicolumn{7}{|c|}{ Proper handling of documents } \\
\hline Yes & $37(41.6 \%)$ & 43.35 & $5.41-347.70$ & 25.70 & $2.43-271.26$ & 0.007 \\
\hline No & $52(58.4 \%)$ & 1 & & & & \\
\hline \multicolumn{7}{|c|}{ Preventive maintenance } \\
\hline Yes & $53(59.5 \%)$ & 16.53 & $2.16-130.95$ & 9.34 & $1.15-80.95$ & 0.043 \\
\hline No & $36(40.5 \%)$ & 1 & & & & \\
\hline \multicolumn{7}{|c|}{ Staff regular meetings } \\
\hline Yes & $15(16.8 \%)$ & 4.39 & $1.456-18.21$ & 4.77 & $1.18-19.19$ & 0.028 \\
\hline No & $74(83.2 \%)$ & 1 & & & & \\
\hline \multicolumn{7}{|c|}{ Review of customer satisfaction } \\
\hline Yes & $16(7 \%)$ & 12.37 & $3.73-41.07$ & 15.24 & $2.88-80.83$ & 0.001 \\
\hline No & 73 (93\%) & 1 & & & & \\
\hline \multicolumn{7}{|c|}{ Quality plan } \\
\hline Yes & $18(20.2 \%)$ & 6.88 & $2.16-21.95$ & 4.70 & $1.37-16.07$ & 0.014 \\
\hline No & $71(79.8 \%)$ & 1 & & & & \\
\hline \multicolumn{7}{|l|}{ IQC } \\
\hline Yes & $64(72 \%)$ & 11.12 & $3.23-38.33$ & 5.3 & $0.98-28.77$ & 0.053 \\
\hline No & $25(28 \%)$ & 1 & & & & \\
\hline \multicolumn{7}{|c|}{ Review of EQA feedback } \\
\hline Yes & $39(43.8 \%)$ & 33.29 & $4.176-27.38$ & 34.882 & $4.23-287.54$ & 0.000 \\
\hline No & $50(56.2 \%$ & I & & & & \\
\hline \multicolumn{7}{|c|}{ Test verification } \\
\hline Yes & $32(36 \%)$ & 3.74 & $1.28-10.97$ & 4.074 & $1.16-14.36$ & 0.029 \\
\hline No & $57(64 \%)$ & $\mathrm{I}$ & & & & \\
\hline \multicolumn{7}{|c|}{ Specimen management guidelines } \\
\hline Yes & $43(48.3 \%)$ & 6.44 & $1.91-21.67$ & 5.909 & $1.48-23.60$ & 0.012 \\
\hline No & $56(51.7 \%)$ & I & & & & \\
\hline \multicolumn{7}{|c|}{ Utilization of quality indicators } \\
\hline Yes & $54(60.6 \%)$ & 4.78 & $1.53-14.97$ & 4.717 & $1.18-18.79$ & 0.028 \\
\hline No & $35(39.4 \%)$ & $\mathrm{I}$ & & & & \\
\hline
\end{tabular}

Abbreviations: SSOP, system standard operating Procedure; IQC, internal quality control; EQA, external quality assessment; COR, crude odd ratio; AOR, adjusted odd ratio.

Based on the reviewed data, this study revealed that the number of laboratories is very low on implementation of personnel factors like employee recognition, 16 $(18 \%)$, the existence of a system for staff motivation, 15 (16.9\%), availability of job description, $17(19.2 \%)$, and competence of staff performance, which is similarly indicated in other studies. ${ }^{18,19}$

Regarding quality assurance practice, this study also indicated few laboratories conducted internal audits, 10 (11.2\%), and performed laboratory method verification, 
$16(18 \%)$. However, participation of laboratories is higher in the EQA program (97\%) and established TAT (88.8\%) which is similar to the study held in Thailand. ${ }^{20}$

In this study, the current LQMS status with its score is identified through the assessment of quality essential elements. From the total participating health center laboratories, $71(79.8 \%)$ scored $0-105$ points (0 star), $6(6.7 \%)$ scored 106-124 points (star 1), 9 (10.1\%) scored 125-143 points (star 2), and 3 (3.4\%) scored 144-162 points (star 3). From this finding, the variation of the star levels indicates the difference in the implementation of a laboratory quality management system, which in turn implies the difference in the provision of laboratory quality service.

This study is inconsistent with studies done in Tanzania, Addis Ababa, and Lesotho in which the proportion of the health facilities and the star they achieved are not comparable. The possible variation might be, the studies conducted in other areas included hospitals and health centers in contrast to this study which was held only in health centers. The other reason might be that baseline, mentorship, and exit assessments were done using full AFRO-Checklists in other studies which were not used in this study. ${ }^{18,21,22}$

Regarding the implementation of quality system essentials, the highest performance was achieved in facility and safety (63.13\%), purchasing and inventory (57.9\%), and documents and records (43.5\%). This study was almost similar to the study conducted in Addis Ababa in which facility and safety and documents and records achieved the highest scores among the 12 quality essentials. ${ }^{18}$

In this study, several factors that affect quality laboratory service were identified: preventive maintenance, review of customer satisfaction, verification of test results, availability of specimen guidelines, availability of SSOP, availability of established quality indicators, and quality plan.

Those health centers which perform equipment maintenance regularly were 9.3 times more likely to provide improved quality service than those which do not perform. This study is similar to studies in other areas, where equipment maintenance and calibration challenges were factors in the provision of quality services. ${ }^{18,23}$ Maintenance and calibration of equipment should be performed according to manufacturer instruction and SOP to prevent major non-conformance that directly affects the laboratory quality of quantitative results.

However, this study is not supported by the studies conducted in Hawassa and Addis Ababa in which equipment maintenance and calibration were not seen as significant in association with laboratory quality service. ${ }^{19,24}$

The possible causes of variation might be due to the difference in the LQMS implementation program, which was not stated in the study conducted in Hawassa. Method of data collection and the difference in the level of health facilities included in the study might be other factors that contributed to the variation.

In this study, a review of client satisfaction and regular staff meetings were observed as two of the variables that were strongly associated with improved quality service. Laboratories that reviewed client satisfaction and conducted staff meetings were 15.24 and 4.76 times more likely to contribute in provision of quality laboratory service, respectively, than those which did not. The ultimate goal of laboratory quality management system implementation toward accreditation is to satisfy our clients by providing quality service as per the standards.

The above findings were comparable with the study done in Addis Ababa in which client satisfaction surveys and regular staff meetings had a direct relationship with the success of quality service improvement toward accreditation. ${ }^{18}$

However, the above result was not consistent with the study conducted in Hawassa, which did not reveal a statistically significant association with laboratory quality outcome. ${ }^{24}$ The variation might be the type and size of the sample, sampling technique, and method of data collection in which interview of laboratory professionals and record review was used in Hawassa in contrast to this study in which data was retrospectively extracted only by document and record reviews.

Verification of results was another factor associated with improved laboratory services. Laboratories that showed evidence of test verification were 4.074 times more likely to provide improved laboratory quality service than those in which evidence of test verification was not observed. This study is shared with the previous study done in public and private health facilities in Addis Ababa in which verification of patient results before release is one of the critical factors. ${ }^{19}$ Because of a no error-free laboratory, verification of the patient results before release is a primary action in the post-analytical phase of quality assurance which prevents any transcriptional error, misdiagnosis, and mistreatment.

Availability of SSOP and guidelines were significantly observed in a direct relationship with improved laboratory quality service, in which facilities utilizing SSOP and specimen guidelines were 7.5 and 5.9 times more likely 
to contribute to providing quality service, respectively, which is consistent with a study done in another area. ${ }^{25}$ This implies that developing and adherence to guidelines, systems, and technical SOPs, as well as proper handling of laboratory documents, play a significant role in the provision of quality laboratory service.

However, these findings are not shared with the study done in public and private health facilities in Addis Ababa. ${ }^{19}$ The possible cause of inconsistency might be that this study was conducted in public health facilities contrary to the study in Addis Ababa, which included private health facilities in which the quality management system implementation program awareness might vary compared to the public health facilities.

The quality plan was significantly associated with the effective provision of improved laboratory service with good implementation of a laboratory quality management system. Laboratories that revealed evidence of available quality plans and utilization of quality indicators were 4.69 and 4.72 times, more likely to contribute to the reliability of laboratory quality service improvement respectively. This study is similar to the previous study conducted in other areas which revealed that this finding shared a direct relationship with QMS implementation of the quality goal and stipulation of laboratory quality service. ${ }^{16}$

The establishment and utilization of quality indicators are used to measure and monitor the overall performance of the laboratory, which ultimately contributes to quality improvement.

\section{Limitation of the Study}

In this study, baseline assessment and regular follow-up of the progress after enrollment in LQMS for all included health facilities were not done, which would not be able to observe the impact of mentorship in quality service improvement. Only a nationally adopted LQMS assessment checklist was used and AFRO-Checklists, which is the essential tool for the assessment of LQMS implementation through SLIPTA, was not used. This study was solely done in health center laboratories and did not include hospital laboratories in which LQMS is more likely implemented. This limitation resulted in a lack of adequate literatures on a similar study for comparing the findings. Data were not collected from all LQMS enrolled health centers due to the security issue in the area at the period of data collection.

\section{Conclusions and Recommendations}

Based on the assessment of the current LQMS status by the nationally adopted LQMS assessment checklist for health center laboratories, the impact of its implementation on quality service is very critical. The majorities of the laboratories scored zero-stars and few of them achieved the minimum and greater star needed for laboratory quality service. Since zero-star level indicates the lowest laboratory performance, supportive supervision and mentorship by regional laboratories to improve quality of laboratory service is valuable. In this study, the significant contributing factors were preventive maintenance, review of customer satisfaction, verification of test results, availability of specimen guidelines, adherence to SOP, availability of established quality indicators, and quality plan. Based on the observation and assessment by LQMS assessment checklist, the lowest score achieved in implementing quality essentials is seen in occurrence management and personnel management. Since any one of the essentials affects quality management system implementation, all are needed to be practiced in participating health center laboratories according to standards. These non-conformities desperately affect the quality of laboratory service and result in poor customer satisfaction. Equipment preventive maintenance and verification of results are major non-conformances that are directly related to patient outcomes and need to be implemented regularly. Hence, regular follow-up, mentorship, supportive supervision by regional laboratories and facility management are unquestionable to provide technical and managerial support for the successful implementation of LQMS. Further study that includes both hospitals and health centers should be conducted by AFRO-Checklists after effective mentorship and regular follow-up to evaluate continual improvement.

\section{Abbreviation}

AFRO, Regional Office for Africa; EQA, External Quality Assessment; ISO, International Organization for Standardization; LQMS, Laboratory Quality Management System; SSOP, System standard operating procedure; SOP, Standard operating procedure; TAT, Turnaround time; SLIPTA, Stepwise Laboratory Improvement toward Accreditation

\section{Ethical Approval and Consent to Participate}

Ethical clearance was obtained from the Oromia Regional Health Bureau Ethical Review Board. The research protocol was reviewed by Oromia Regional Health Bureau 
Ethical Review Board and confirmed that the problem actually existed and the study would ultimately come up with a possible recommendation. A formal letter was also written to each health center by the Oromia Regional Health Bureau ethics review committee to legalize the study in compliance with the National Health Research ethics review committee so that the confidentiality of the patient data could be ensured.

\section{Acknowledgment}

We would like to extend our deepest appreciation and gratitude to Oromia Regional Health Bureau for its financial and logistics contribution and for the provision of the ethical clearance to effectively conduct the study. Our special thanks have also been extended to all health center laboratory professionals and facility managements who tirelessly provided valuable information during the period of data collection.

\section{Disclosure}

The authors declare that they have no competing interests in this work.

\section{References}

1. Onceptualization C, Hemes RET, Berner M, Maedche A, Mueller B. Stepwise laboratory quality improvement process towards accreditation (SLIPTA) Checklist; 2012:48. Available from: https://www.afro. who.int/sites/default/files/2017-06/slipta-checkist0711.pdfhttps://who. insomnation.com/sites/default/files/pdf/slipta-checkist0711.pdf

2. Maruta T, Ndlovu N, Albalak R, Alemnji G. The impact of stepwise Laboratory improvement Toward Accreditation in improving laboratory quality system in caribbean region.African Journal of laboratory medicine . 2016;3(2).

3. World Health Organization laboratory quality management system handbook; 2011 Available from http://apps.who.int/iris/bitstream/han dle/10665/44665/9789241548274_eng.pdf;jsessionid= DC216E1E955A85CF60991C5FEED9E57E? sequence=1. Accessed June 14, 2021.

4. Tamil SM, Srinivas A. Evaluation of quality management systems implementation in medical diagnostic laboratories benchmarked for accreditation. J Med Lab Diagn. 2015;6(5):27-35. doi:10.5897/ JMLD2015.0104

5. Nthenge ML. Factors Affecting Quality Management in Public Institutions: a Case Study of Machakos University, Kenya. Journal of Food Science and Quality Managment2016;58(2003):63-66.

6. Davies J, Abimiku A, Alobo M, et al. Sustainable clinical laboratory capacity for health in Africa. Lancet Glob Heal. 2017;5(3):e248-9. doi:10.1016/S2214-109X(17)30024-4

7. World Health Organization. Delivering quality health services [Internet]. World Health Organization, World Bank Group, OECD; 2018. 1-100 p. Available from: http://apps.who.int/bookorders. Accessed June 14, 2021.

8. Albert H, De Dieu Iragena J, Kao K, Erni D, Mekonen T, Onyebujoh PC. Implementation of quality management systems and progress towards accreditation of National Tuberculosis Reference Laboratories in Africa. Afr J Lab Med. 2017;6(2):1-8. doi:10.4102/ ajlm.v6i2.490
9. Elbireer AM, Opio AA, Brough RL, Jackson JB, Manabe YC. Strengthening public laboratory service in sub-Saharan Africa: uganda case study. Lab Med. 2011;42(12):719-725. doi:10.1309/ LM2OBNYY9D0UXZJO

10. Lulie AD, Hiwotu TM, Mulugeta A, et al. Perceptions and attitudes toward SLMTA amongst laboratory and hospital professionals in Ethiopia. Afr J Lab Med. 2014;3(2):1-6. doi:10.4102/ajlm.v3i2.233

11. Ethiopian Health and Nutrition Institute.Master plan for the public health laboratory system in Ethiopia :Addis Ababa,2009.

12. ESA. Ethiopian standard: health Center- Requirements. ES 3611:2012. First edition; 2012:1-126.

13. World Health Organization. World malaria report 2016. World Heal Organ; 2016:186.

14. Annual activity report Oromia Regional Health Bureau; 2018.

15. Piggott MWK Importance of quality management systems to laboratory reliability: caribbean med labs foundation5thccas workshop; 2008. available from http://www.hivgateway.com/files/ e288624c983f2f7c96379fdef52ce59b/Importance_of_Quality_ Management_Systems_to_Laboratory_Reliability.pdf. Accessed June 14, 2021.

16. Adebabay T, Submitted T, Fulfillment P, Health P. Assessment of implementation of quality management system and factors affecting implementation in public hospitals, Amhara region, Addis Ababa University College of Health Sciences School of Public Health Assessment of implementation of quality manageme. AAU Inistitutional Respository .2017;1-72.

17. Girma M, Desale A, Hassen F, Sisay A, Tsegaye A. Survey-defined and interview-elicited challenges that faced ethiopian government hospital laboratories as they applied ISO 15189 accreditation standards in resource-constrained settings in 2017. Am J Clin Pathol. 2018;150(4):303-309. doi:10.1093/ajcp/aqy049

18. Sisay A, Mindaye T, Tesfaye A, Abera E, Desale A. Assessing the outcome of Strengthening Laboratory Management Towards Accreditation (SLMTA) on laboratory quality management system in city government of Addis Ababa, Ethiopia. Pan Afr Med J. 2015;20:314. doi:10.11604/pamj.2015.20.314.5375

19. Mesfin EA, Taye B, Belay G, Ashenafi A, Girma V. Factors Affecting Quality of Laboratory Services in Public and Private Health Facilities in Addis Ababa, Ethiopia. Ejifcc. 2017;28(3):205-223.

20. Wattanasri N, Manoroma W, Viriyayudhagorn S. Laboratory Accreditation in Thailand: a systemic approach. Am J Clin Pathol. 2010;134(4):534-540. doi:10.1309/AJCPZYY19WMKMAZT

21. Andiric LR, Massambu CG. One laboratory's progress toward accreditation in Tanzania. Afr $J$ Lab Med. 2014;3(2):2-5. doi:10.4102/ajlm.v3i2.202

22. Mothabeng D, Maruta T, Lebina M, Lewis $\mathrm{K}$, Wanyoike J, Mengstu Y. Strengthening laboratory management towards accreditation: the lesotho experience. Afr J Lab Med. 2011;1(1). doi:10.4102/ ajlm.v1i1.9

23. Tegbaru B, Meless H, Tamene W, et al. The status of HIV screening laboratories in Ethiopia: achievements, problems encountered and possible solutions. Ethiop J Heal Dev. 2002;16(2).

24. Fenta DA, Ali MM. Factors affecting quality of laboratory result during ordering, handling, and testing of the patient's specimen at hawassa university college of medicine and health science comprehensive specialized hospital. $J$ Multidiscip Healthc. 2020;13:809-821. doi:10.2147/JMDH.S264671

25. Ababa A, Health P, Ababa A. Factors affecting implementation of laboratory quality management system in. J Trop Dis Public Health. 2019;8(343):1-9. 


\section{Publish your work in this journal}

Pathology and Laboratory Medicine International is a peer-reviewed, open access journal focusing on innovative basic research and translational research related to pathology or human disease. The journal includes original research, updates, case reports, reviews and commentaries on current controversies. The manuscript management system is completely online and includes a very quick and fair peer-review system. Visit $\mathrm{http} / / / \mathrm{www}$.dovepress.com/testimonials.php to read real quotes from published authors.

Submit your manuscript here: https://www.dovepress.com/pathology-and-laboratory-medicine-international-journal 